\title{
Efficacy of locally-delivered statins adjunct to non-surgical periodontal therapy for chronic periodontitis: a Bayesian network analysis
}

Ruoyan Cao ${ }^{1}$, Qiulan $\mathrm{Li}^{2}$, Yu Chen ${ }^{1}$, Mianfeng Yao ${ }^{3}$, Qiqi Wu ${ }^{4}$ and Hongbo Zhou ${ }^{1 *}$

\begin{abstract}
Background: Studies indicate locally-delivered statins offer additional benefits to scaling and root planning (SRP), however, it is still hard to say which type of statins is better. This network meta-analysis aimed to assess the effect of locally-delivered statins and rank the most efficacious statin for treating chronic periodontitis (CP) in combination with SRP.

Methods: We screened four literature databases (Pubmed, Embase, Cochrane Library, and Web of Science) for randomized controlled clinical trials (RCTs) published up to June 2018 that compared different statins in the treatment of chronic periodontitis. The outcomes analyzed were changes in intrabony defect depth (IBD), pocket depth (PD), and clinical attachment level (CAL). We carried out Bayesian network meta-analysis of CP without systemic diseases. Traditional and Bayesian network meta-analyses were conducted using random-effects models.

Results: Greater filling of IBD, reduction in PD, and gain in CAL were observed for SRP treated in combination with statins when compared to SRP alone for treating CP without systemic diseases. Specifically, SRP+ Atorvastatin (ATV) (mean difference [MD]: $1.5 \mathrm{~mm}, 1.4 \mathrm{~mm}, 1.8 \mathrm{~mm}$, respectively), SRP + Rosuvastatin (RSV) (MD: $1.8 \mathrm{~mm}, 2.0 \mathrm{~mm}, 2.1$ $\mathrm{mm}$, respectively), and SRP + Simvastatin (SMV) (MD: $1.1 \mathrm{~mm}, 2.2 \mathrm{~mm}, 2.1 \mathrm{~mm}$, respectively) were identified. However, no difference was found among the statins tested. In CP patients with type 2 diabetic (T2DM) or in smokers, additional benefits were observed from locally delivered statins.

Conclusion: Local statin use adjunctive to SRP confers additional benefits in treating CP by SRP, even in T2DM and smokers. RSV may be the best one to fill in IBD. However, considering the limitations of this study, clinicians must use cautious when applying the results and further studies are required to explore the efficacy of statins in CP with or without the risk factors (T2DM comorbidity or smoking history).
\end{abstract}

Keywords: Statins, Chronic periodontitis, Periodontal therapy, Network meta-analysis

\section{Background}

Chronic periodontitis (CP) is a multifactorial inflammatory disease caused by pathogenic microorganisms and disordered host immune inflammation that leads to bone resorption, bony defects, and ultimately tooth loss [1]. Nonsurgical periodontal treatment reduces pocket

\footnotetext{
* Correspondence: zhb2540@csu.edu.cn

${ }^{1}$ Department of Prosthodontics, Xiangya Stomatological Hospital \& School of Stomatology, Central South University, 72 Xiangya Road, Changsha 410000, China

Full list of author information is available at the end of the article
}

depth (PD) and increases clinical attachment level (CAL) to some extent [2, 3], but fails to fill the bony defect [4]. Thus, various adjuvant therapies have been applied in nonsurgical treatment to reduce tissue destruction and to enhance periodontal reparative processes including statins.

Statins are inhibitors of 3-hydroxy-3-glutaryl-coenzyme A reductase and are primarily used to prevent hyperlipidemia and coronary artery disease [5, 6]. However, with in-depth study of statins, additional benefits have been found in the treatment of periodontal

(c) The Author(s). 2019 Open Access This article is distributed under the terms of the Creative Commons Attribution 4.0 International License (http://creativecommons.org/licenses/by/4.0/), which permits unrestricted use, distribution, and reproduction in any medium, provided you give appropriate credit to the original author(s) and the source, provide a link to the Creative Commons license, and indicate if changes were made. The Creative Commons Public Domain Dedication waiver (http://creativecommons.org/publicdomain/zero/1.0/) applies to the data made available in this article, unless otherwise stated. 
diseases. This phenomenon may be due to the unique properties of statins that limit the pathogenesis of periodontitis, such as anti-inflammatory [7, 8], antimicrobial [9], bone formation promoting, bone loss inhibiting $[10,11]$ and antioxidant properties [12]. Different statins exhibit different such properties, which could lead to different treatment outcomes. For example, rosuvastatin (RSV) is thought to possess stronger antiinflammatory potential than atorvastatin (ATV) [13], while ATV is stronger than simvastatin (SMV) in terms of anti-inflammatory and antioxidant potential $[14,15]$. SMV is considered to be the optimal statin for controlling periodontal pathogens, such as Porphyromonas gingivalis $(P g)$ and Aggregatibacter actinomycetemcomitans $(A a)$ [16]. However, clinical trials investigating the effects of different statins on adjuvant treatment of $\mathrm{CP}$ are limited. To our knowledge, there are six metaanalyses comparing statins adjunctive to scaling and root planing (SRP) with SRP alone, however, they fail to measure the relative effects of various statins on $\mathrm{CP}$ without other systemic diseases [4, 17-21]. Therefore, a network meta-analysis which compares and ranks different statins should be beneficial to clinical practice.

This network meta-analysis aimed to study whether local statins applied adjunctively to nonsurgical periodontal treatment contribute to better clinical and histological periodontal outcomes based on randomized controlled clinical trials (RCTs) when compared to periodontal treatment alone in patients with CP. This study further ranked statins based on their adjunct efficacy with SRP.

\section{Methods}

\section{Protocol registration}

This meta-analysis was prospectively registered at the National Institute for Health Research PROSPERO, International Prospective Register of Systematic Reviews (http://www.crd.york.ac.uk/PROSPERO, registration no.: CRD42018100753).

\section{Inclusion criteria}

Only RCTs followed up for at least 6 months were included in this network meta-analysis. PICO criteria was defined as [22]:

(P) Participants: Patients with chronic periodontitis without periodontal therapy and use of antibiotics in the past 6 months.

(I) Interventions: The following locally delivered statins employed adjunctively to periodontal treatment were considered: SRP + ATV, SRP + SMV, and SRP + RSV

(C) Comparison: SRP alone

(O) Outcome measures: primary outcome: changes in IBD; secondary outcomes: changes in PD and CAL

\section{Exclusion criteria}

Studies that had any of the following characteristics were excluded: (a) split-mouth RCT design; (b) inclusion patients with statin allergy; (c) application of systemic statin therapy; (d) inclusion of immunocompromised individuals; (e) inclusion of former smokers; (f) systemic diseases except for type 2 diabetes.

\section{Search methods for study identification}

To identify RCTs for this network meta-analysis, we searched the Pubmed, Embase, Cochrane Library, and Web of Science databases for relevant publications published up to June 2018. The following MeSH terms/free terms and their combinations searched are described in Additional file 1 . The resulting reference lists of relevant articles and relevant systematic reviews $[4,17-20]$ was manually screened to find other potentially eligible studies.

\section{Data collection, extraction and management}

Two researchers (R.Y.Cao \& Q.L.Li) independently screened the databases search for relevant titles and abstracts. Then data was extracted and recorded relevant information from eligible studies with pre-designed data-extraction forms using the following criteria: surname of the first author, publication year, country, characteristics of participants (age, gender, smoking status, systemic diseases), sample size, type of interventions, number of application sites/patients, application mode/ site, application period, periodontal probe, outcome (IBD, PD, CAL, baseline and mean change in parameters from baseline to follow-up visits). Disagreements on study inclusion or data extraction were resolved through discussion among the researchers. When necessary, a third investigator (M.F.Yao) helped to reach a consensus with all reviewers.

\section{Risk of bias assessment}

The risk of bias of the included studies was performed independently by two researchers (R.Y.Cao \& Q.L.Li) using the Cochrane Collaboration tool [23]. Any disagreements were solved by the third investigator (M.F.Yao).

\section{Statistical analysis}

The treatment outcomes were measured as the absolute difference (AD) in IBD, PD, and CAL in at least 6 months after periodontal treatment. When standard deviations (SD) for the outcomes parameters were not available, they were calculated by assuming the correlation coefficient to be 0.5 as previously described [24]. Based on patient characteristics, the studies were divided into three subgroups (systemic healthy, T2DM, and smokers). Network meta-analysis was only applied to the systemic healthy subgroup as there were two studies in 
other subgroups. The same follow-up duration was used in this meta-analysis in the subgroups.

First, we developed a random-effects pairwise metaanalysis in Stata 14.2 (Stata Corporation, College Station, TX, USA). Weighted mean difference (WMD) and 95\% confidence intervals (CIs) were used to compare continuous variables. Second, Bayesian network metaanalyses were performed by using a random-effect model to pool the effect sizes of both direct and indirect comparisons. Non-informative uniform and normal prior distributions were used throughout the network meta-analysis. Markov chain Monte Carlo methods with four chains of 300,000 iterations after a burn-in phase of 100,000 iterations was performed to achieve credible mean difference (MD) and 95\% credible intervals (CrIs). We used CrIs beyond the null value to assess significance and ranked different treatments.

Inconsistency was assessed by comparing direct evidence with indirect evidence from the entire network at each node (node-splitting analysis) with $p<0.05$ [25]. Moreover, we examined the pooled effects from traditional pairwise meta-analysis and network meta-analysis to further verify the consistency of the network. The goodness of fit of the model was tested by calculating the posterior mean residual deviance (Dbar). When the Dbar was similar to the number of data points in the study, the model was considered to fit the data well [26, 27]. Heterogeneity was assessed with $\mathrm{I}^{2}$ calculation. Sensitivity analysis was performed to verify the robustness of our analyses by excluding studies with a high risk of bias then the effect was recalculated. R 3.2.2 (R Foundation for Statistical Computing, Vienna, Austria) GeMTC 0.8 package was used to analyse all data.

\section{Results}

Study selection and the exclusion criteria are summarized in Fig. 1. A total of 126 citations were obtained for title and abstract review. Finally, 14 studies were selected for inclusion that met all the inclusion criteria and were analyzed in a pair-wise meta-analysis. Ten of studies were included in network meta-analysis.

\section{Studies characteristics}

Table 1 and Additional file 2 present the main characteristics of the included studies, all of which were parallel RCTs with a follow-up of 6-9 months. Ten trials included patients without systemic diseases and excluded smokers [28-31, 34, 36, 37, 39-41], two trials concerned patients with T2DM [32, 35] or smokers [33, 38]. All included studies reported clear inclusion criteria and patients with periodontitis had similar intrabony defects, $\mathrm{PD}$, and CAL in each subgroup. All studies employed a

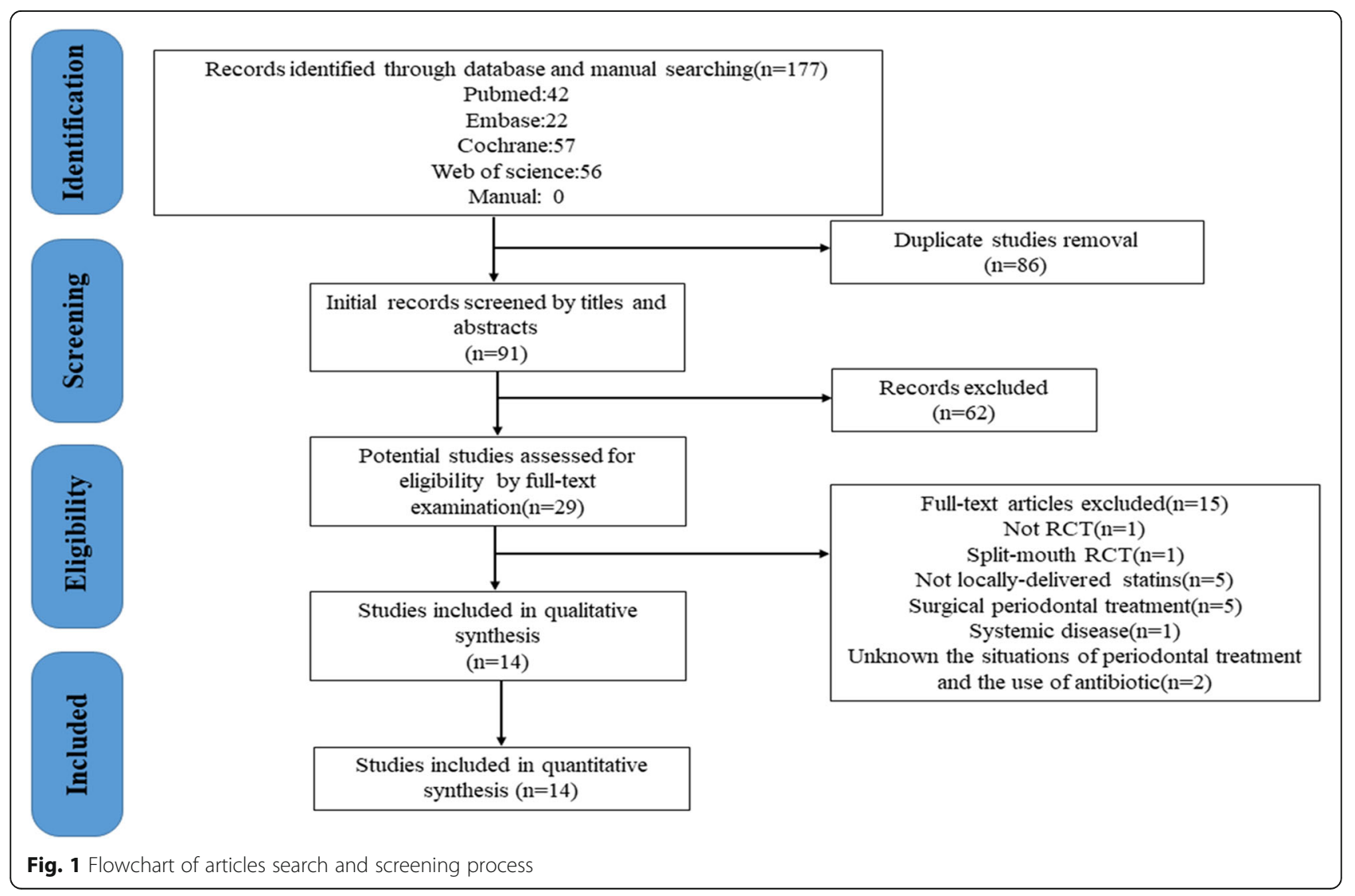




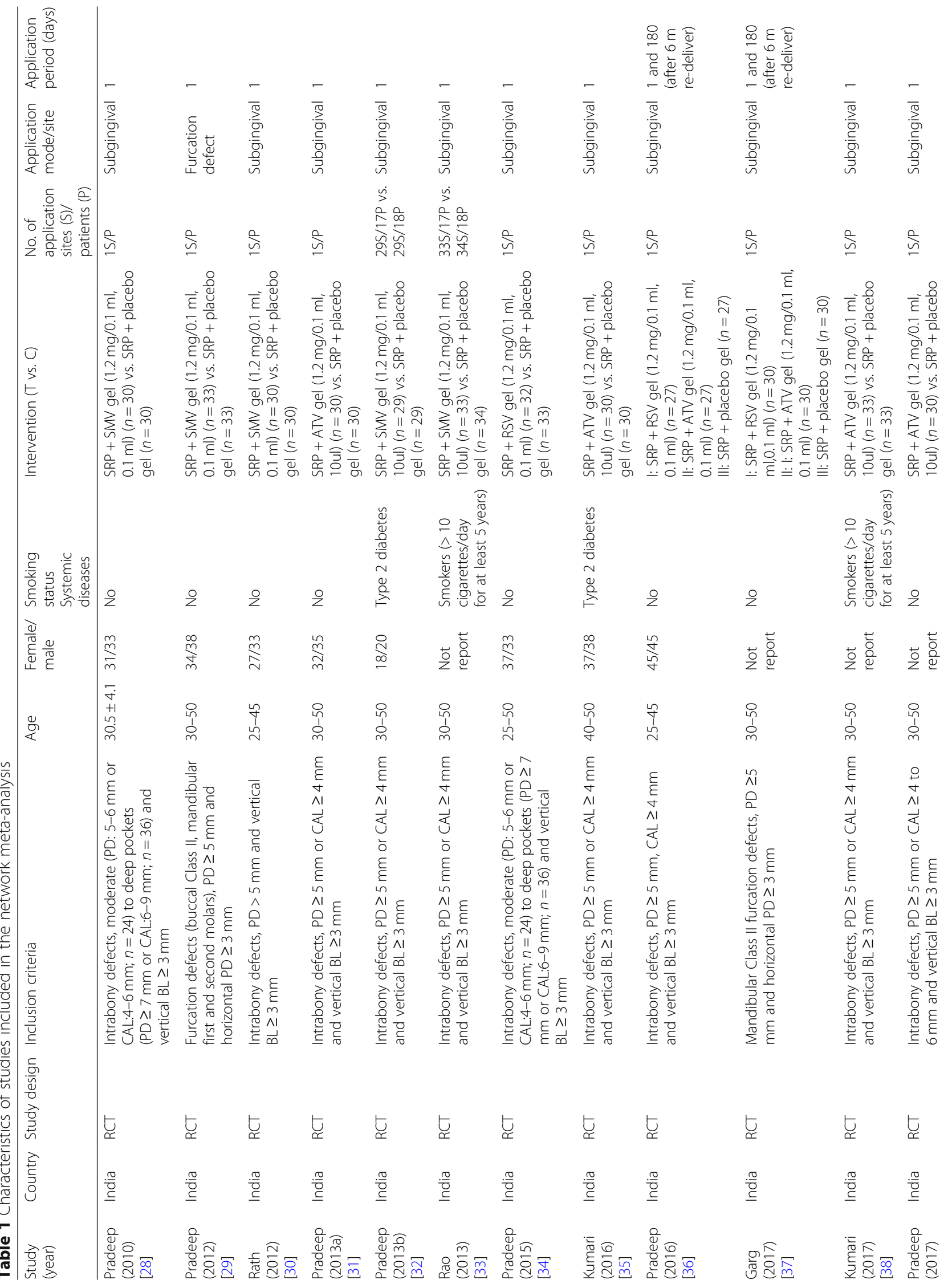




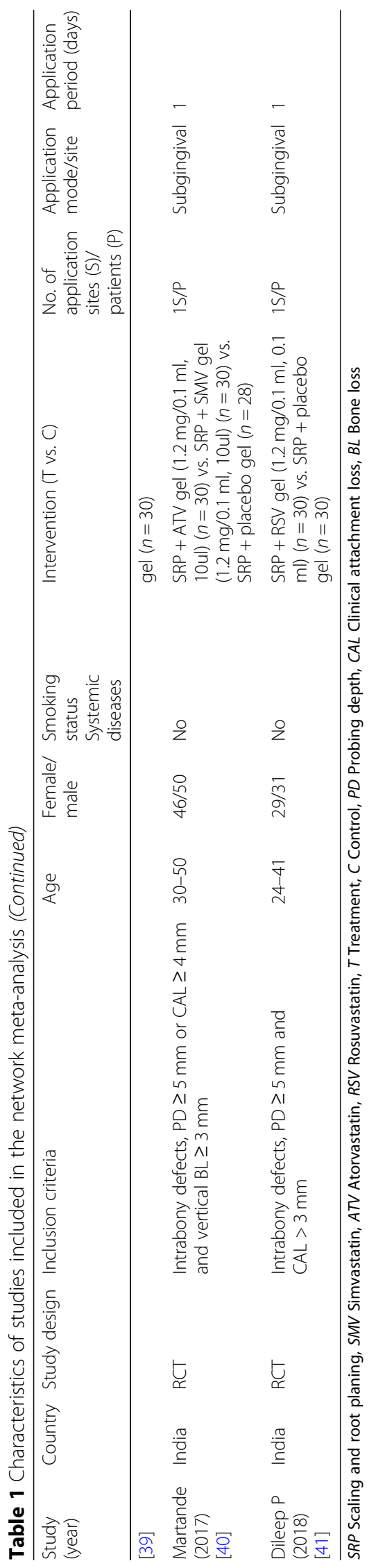


$1.2 \%$ statin gel with a dose of $0.1 \mathrm{ml}$ or $10 \mu \mathrm{l}$. In two studies [36, 37], the statin gel was applied after SRP and re-applied again 6 months after while others applied statin gel only once after SRP. There were no adverse events observed in all trials. Figure 2 shows the weighted network.

\section{Risk of bias in included studies}

Additional file 3 details the quality of each of the 14 RCTs. All the trials described the methods of sequence generation, two trials used coin toss $[28,30]$, and the rest used a computer-generated random table. Seven trials employed allocation concealment [31-35, 37, 38]. All studies reported whether participants or study personnel were blinded, and three studies [30, 40, 42] did not report whether these groups were blinded to outcome assessment. After considering such little incomplete outcome data, reporting bias and other bias domains, all studies had a low risk of bias.

\section{Synthesis of results}

\section{Effects of statins in subjects without systemic diseases}

Ten trials were included for $\mathrm{CP}$ without systemic diseases, and the results of standard pairwise meta-analysis and network meta-analysis are presented (Additional file 4, Fig. 3). Changes in periodontal parameters (IBD, PD, and CAL) were significant higher in SRP + SMV/ATV/RSV group than in SRP group alone in both pairwise and network meta-analysis. No significant difference was found in the changes in IBD, PD, and CAL in network meta-analysis.

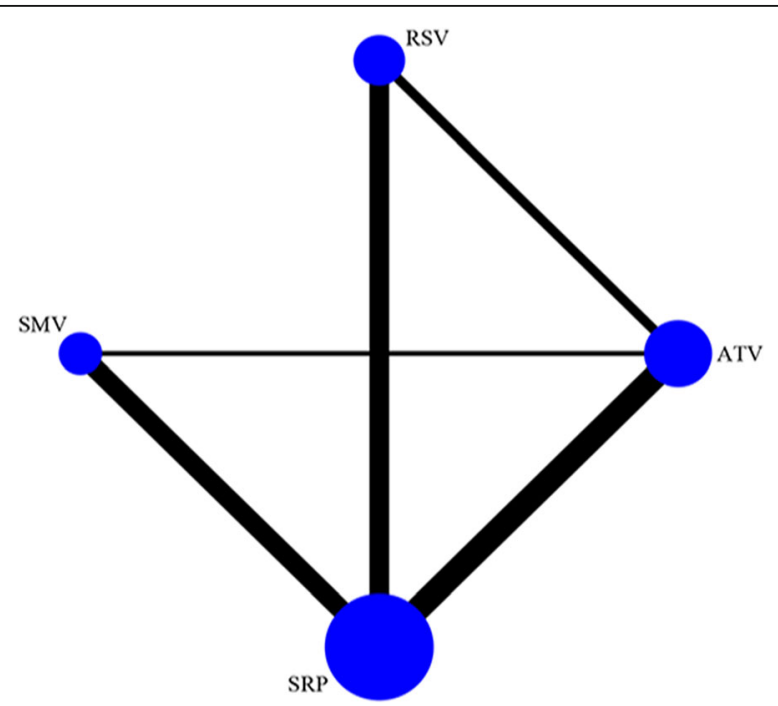

Fig. 2 Network of the interventional comparisons for the Bayesian network analysis. The size of the nodes is proportional to the number of subjects (sample size) randomized to receive the therapy. The width of the lines is proportional to the number of trials comparing each pair of treatments. SRP, scaling and root planing; SMV, simvastatin; ATV, atorvastatin; RSV, rosuvastatin
RSV was ranked as the best statin in terms of IBD outcomes while SMV ranked the best for PD and CAL outcomes (Fig. 4). Network meta-analysis showed considerable heterogeneity with global $\mathrm{I}^{2}>90$ (Table 2 ).

\section{Effects of statins in other subgroups}

Additional file 4 shows the results of traditional metaanalysis. For patients with T2DM, SRP + statins showed additional benefits in IBD fill (WMD: $1.39 \mathrm{~mm}$; 95\% CI: $1.25-1.53 ; \mathrm{I}^{2}=0.0 \%$ ), PD reduction (WMD: $2.37 \mathrm{~mm}$; 95\% CI: $1.97-2.78 ; \mathrm{I}^{2}=0.0 \% \%$ ), and CAL gain (WMD: $2.69 \mathrm{~mm}$; 95\% CI: 2.26, 3.12; $\mathrm{I}^{2}=0.0 \%$ ). For smokers, significantly greater benefits were observed with SRP + statins treatment for IBD (WMD: $1.35 \mathrm{~mm}$; 95\% CI: 1.24-1.46; $\mathrm{I}^{2}=0.0 \%$ ), PD (WMD: $2.62 \mathrm{~mm} ; 95 \% \mathrm{CI}$ : 1.97-3.28; $\mathrm{I}^{2}=67.2 \%$ ), and CAL (WMD: $2.18 \mathrm{~mm}$; $95 \%$ CI: $\left.1.72-2.64 ; \mathrm{I}^{2}=0.0 \%\right)$.

\section{Evaluation of consistency and fit of the models}

The results of pairwise and network meta-analysis are presented in Additional file 5 and Fig. 3. The effect size and relevant $\mathrm{CI}$ or $\mathrm{CrI}$ were found to be similar between pairwise and network meta-analyses. The result of nodesplitting analysis showed no inconsistency (Additional file 6) and the data was well-fitted to the model with Dbar approximation of the data points in PD reduction, CAL gain and IBD fill (Additional file 5).

\section{Sensitivity analysis}

After excluding three studies with high risk of bias [28, $29,41]$, the results were not significantly altered (Additional file 6).

\section{Discussion}

Statins, possess anti-inflammatory, anti-microbial, osteosimulative, and antioxidant properties which may partly account for their beneficial effects in treating CP. Statins were shown to suppress inflammatory factors associated with periodontitis such as IL-6, TNF- $\alpha$ [43], IL-1 $\beta$ [44], as well as periodontal pathogens $P g$ and $A a$ [45]. Statins could also inhibit the secretion of matrix metalloproteinases (MMPs) [46], which are involved in the destruction of periodontal tissue. Moreover, statins increase bone regeneration by inducing the expression of BMP-2, VEGF, and OPG $[47,48]$. Thus, it is unsurprising that local use of statins provides additional benefits for periodontal parameters of $\mathrm{CP}$ with or without systemic disease.

Traditional meta-analyses fail to measure the relative effect as they only synthesize studies with the same pair of comparators; network meta-analyses have been proposed to overcome this drawback. In our study, we performed a Bayesian network meta-analysis to compare the relative effect of different statins and found their efficacy to be similar, consistent with a study by Muniz et 


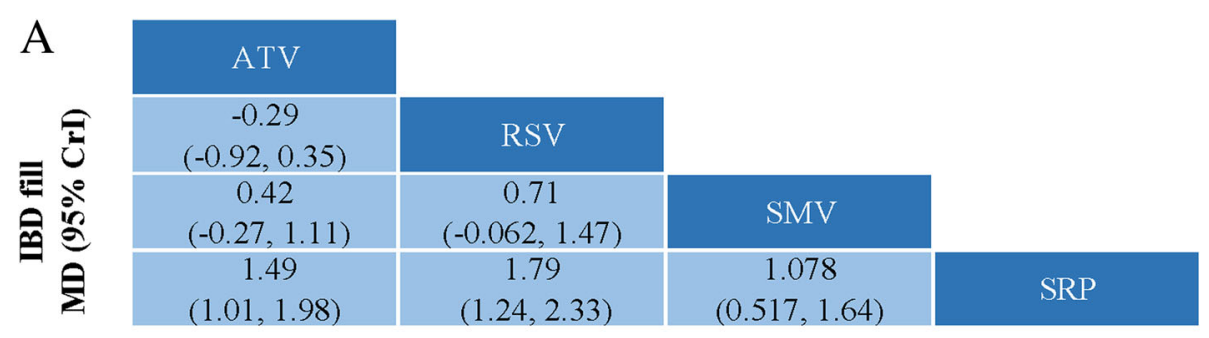

B

CAL gain

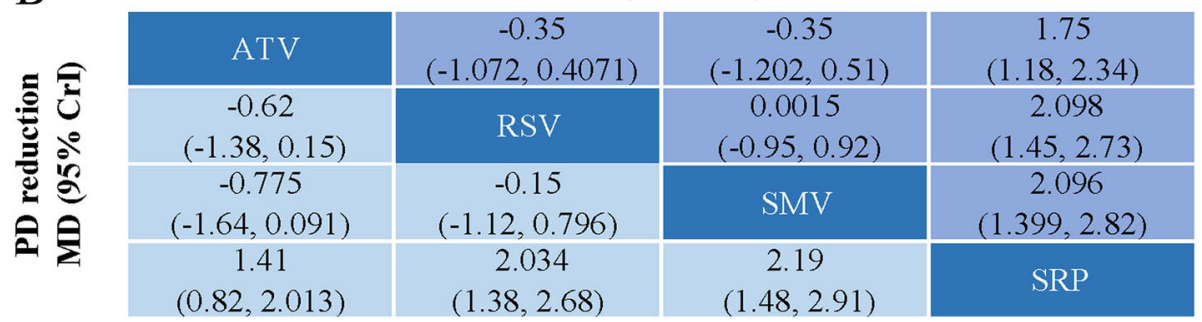

Fig. 3 Multiple-treatment comparisons for $\triangle P D, \triangle C A L, I B D$ fill in $C P$ without systemic diseases. PD, probing depth; CAL, clinical attachment loss; IBD, intrabony defect; SRP, scaling and root planing; SMV, simvastatin; ATV, atorvastatin; RSV, rosuvastatin

al. [20] who used meta-regression. Contrastingly, a study by Bertl et al. [4] found that RSV was more efficacious than SMV for all parameters tested and ATV in all parameters except for residual IBD. However, Bertl et al. [4] included patients with different characteristics and different periodontal therapy which may partially account for this inconsistency with our results. More direct evidence is needed in further test and compare the efficacy of different statins.

In addition, another advantage of network metaanalysis is that Bayesian chain assists in ranking the treatment efficacy by measuring the corresponding probability [49], so that it could provide more evidence to guide clinicians. Though we found no difference between diverse statins, ranking can pave the way for understanding the differences in opinions on the use of either statin in periodontal disease. Our results indicate that SMV is ranked the best in PD reduction and CAL gain. SMV is considered to be the best statin against periodontal pathogens such as $P g$ and $A a$. Moreover,
SMV was observed to decrease the expression of MMP1, MMP-3, MMP-8, MMP-9 and MMP-13 [50-52]. RSV may be the best optimal performer in terms of IBD fill. Additionally, RSV has a greater anti-inflammatory action due to more effective suppression of $\mathrm{C}$-reactive protein levels. Moreover, RSV is more effective in reducing lowdensity lipoprotein cholesterol which had benefits in induced periodontitis in hypertensive rats via inflammatory gene profile modulation [53].

We also assessed the efficacy of adjunctive statins in $\mathrm{CP}$ with T2DM comorbidity or smoking history as these are both risk factors for CP. High levels of blood-glucose increase advanced glycation end-products (AGE) and receptor of AGE (RAGE) leading to an exaggerated inflammatory response and periodontal tissue destruction by oxidative mechanisms $[54,55]$. Smoking can similarly upregulate the expression of RAGE [56, 57]. Statins possess strong antioxidant properties which may improve treatment outcomes for $\mathrm{CP}$ patients with T2DM or those who smoke. Existing RCTs indicate that locally applied ATV or

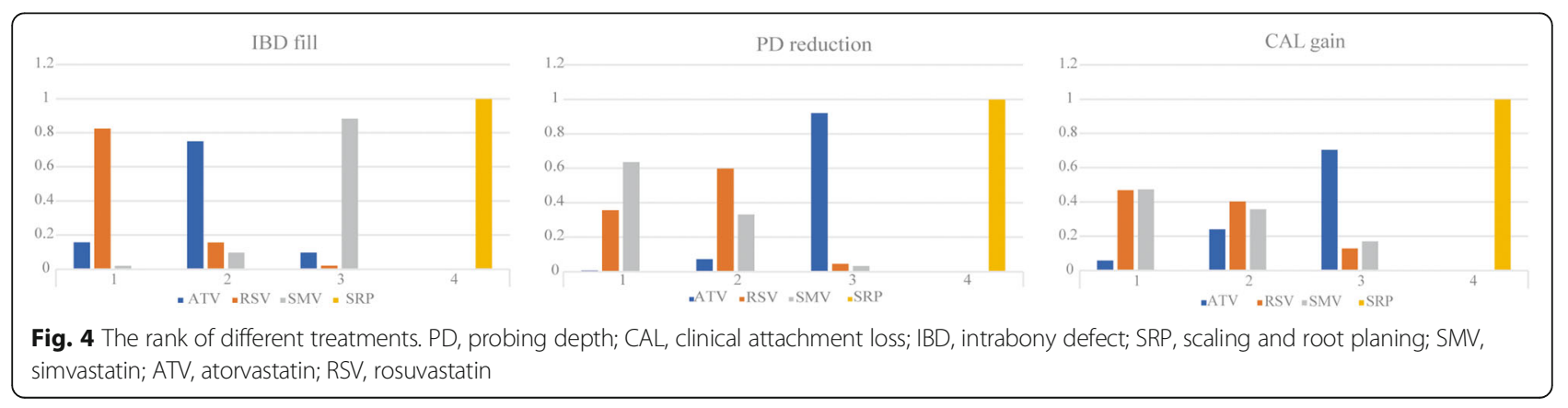


Table 2 Analysis of heterogeneity

\begin{tabular}{|c|c|c|c|c|}
\hline t1 & t2 & i2.pair & i2.cons & incons.p \\
\hline \multicolumn{5}{|l|}{ PD } \\
\hline \multicolumn{5}{|c|}{ Per-comparison I-squared } \\
\hline ATV & SRP & 86.12230 & 86.70305 & NA \\
\hline RSV & SRP & 97.77175 & 97.30109 & NA \\
\hline SMV & SRP & 73.65906 & 76.46786 & NA \\
\hline ATV & RSV & 0.00000 & 25.43579 & 0.45083148 \\
\hline ATV & SMV & NA & 88.02565 & 0.08914125 \\
\hline Global I-squared & & 93.72891 & 92.04248 & \\
\hline \multicolumn{5}{|l|}{ CAL } \\
\hline \multicolumn{5}{|c|}{ Per-comparison I-squared } \\
\hline ATV & SRP & 90.50355 & 91.37052 & NA \\
\hline RSV & SRP & 99.36135 & 99.10428 & NA \\
\hline SMV & SRP & 12.06329 & 13.87502 & NA \\
\hline ATV & RSV & 0.00000 & 53.34930 & 0.3627355 \\
\hline ATV & SMV & NA & 68.13125 & 0.2851176 \\
\hline Global I-squared & & 97.86568 & 96.677 & \\
\hline \multicolumn{5}{|l|}{ IBD } \\
\hline \multicolumn{5}{|c|}{ Per-comparison I-squared } \\
\hline ATV & SRP & 95.00764 & 94.65418 & NA \\
\hline RSV & SRP & 97.78225 & 97.79998 & NA \\
\hline SMV & SRP & 83.90910 & 82.98919 & NA \\
\hline ATV & RSV & 0.00000 & 0.00 & 0.8532051 \\
\hline ATV & SMV & NA & 0.00000 & 0.6941173 \\
\hline Global I-squared & & 95.30703 & 94.33677 & \\
\hline
\end{tabular}

PD Probing depth, CAL Clinical attachment loss, IBD Intrabony defect, SMV Simvastatin, ATV Atorvastatin, RSV Rosuvastatin, $t 1$ Treatment 1, $t 2$ Treatment 2, i2.pair i-square of pair-wise meta-analysis, i2.cons i-square of network metaanalysis, incons.p inconsistency $p$-values for pairwise and network metaanalysis, NA Not applicable

SMV adjunctive to SRP was more effective than SRP alone in CP patients with T2DM or in smokers [32, 33, 35, 38]. The results of our traditional meta-analyses also support these findings and is consistent with another meta-analysis conducted by Ambrósio et al. [19]. However, the sample size in these trials was too small to draw a strong conclusion and more high-quality RCTs are needed to further to validate our results.

We observed a high degree of heterogeneity in $\mathrm{CP}$ patients without other systemic diseases. This may be attributable to variables such as different gel doses of statins used for treatment $(0.1 \mathrm{ml}$ or $10 \mathrm{ul})$ in the included trials. In addition, the measurement of IBD from the conventional radiographs was not calibrated which may have caused geometric errors in assessing IBD fill.

\section{Limitations}

This network meta-analysis has several limitations that should be noted. Firstly, the length of follow-up of the included trials were relatively short. Secondly, the sample sizes (28-34) for each group were relatively small. Finally, the heterogeneity was high despite decreasing the discrepancy among the characteristics of patients. Multi-centered RCTs with larger sample size and with an extended follow-up duration up to 12 or 24 months are needed to confirm the beneficial effects of statins in combination with nonsurgical periodontal treatment for $\mathrm{CP}$.

\section{Conclusions}

Taken together, this meta-analysis shows that SRP + ATV/RSV/SMV confers additional benefits in treating CP by SRP. However, clinicians must be cautious in applying these conclusions as further studies are required for validation of these results.

\section{Additional files}

Additional file 1: Search strategy used in PubMed/MEDLINE. (DOCX $14 \mathrm{~kb}$ ) Additional file 2: Outcomes of studies included in the network metaanalysis. (DOCX $22 \mathrm{~kb}$ )

Additional file 3: Risk of bias summary: review authors' judgements about each risk of bias item for each included study. (DOCX 35 kb)

Additional file 4: Forest plot on the effect size of subgroups. (DOCX 688 kb)

Additional file 5: Evaluation of consistency and fit of the models. (DOCX 3596 kb)

Additional file 6: Sensitivity analysis of outcomes by excluding trials with a high risk of bias. (DOCX $148 \mathrm{~kb}$ )

\section{Abbreviations}

Aa: Aggregatibacter actinomycetemcomitans; AD: Absolute difference; AGE: Advanced glycation end-products; ATV: Atorvastatin; CAL: Clinical attachment level; Cls: Confidence intervals; CP: Chronic periodontitis; Dbar: Posterior mean residual deviance; IBD: Intrabony defect depth; MD: Mean difference; PD: Pocket depth; Pg: Porphyromonas gingivalis; RAGE: Receptor of AGE; RCT: Randomized controlled clinical trial; RSV: Rosuvastatin; SD: Standard deviations; SMV: Simvastatin; SRP: Scaling and root planning; T2DM: Type 2 diabetes mellitus; WMD: Weighted mean difference

\section{Acknowledgements}

We want to acknowledge Dr. Fei Yan (Central South University) for his help during this manuscript development.

\section{Authors' contributions}

RYC, QLL and MFY were responsible for study selection, quality assessment, data extraction and data synthesis. RYC drafted the manuscript. HBZ, QQW and YC participated in the research design and revision of the manuscript. All authors read and approved the final manuscript.

Funding

There was no funding for this review.

Availability of data and materials

All data generated or analyzed during this study are included in this published article.

Ethics approval and consent to participate

Not applicable.

Consent for publication

Not applicable. 


\section{Competing interests}

The authors declare that they have no competing interests.

\section{Author details}

'Department of Prosthodontics, Xiangya Stomatological Hospital \& School of Stomatology, Central South University, 72 Xiangya Road, Changsha 410000, China. ${ }^{2}$ Department of Stomatology, The Second Xiangya Hospital, Central South University, 139 Middle Renmin Road, Changsha 410011, China.

${ }^{3}$ Department of Oral Medicine, Xiangya Hospital, Central South University, 87 Xiangya Road, Changsha 410083, China. ${ }^{4}$ Department of Operative Dentistry and Endodontics, Stomatological Hospital \& School of Stomatology, Central South University, 72 Xiangya Road, Changsha 410000, China.

\section{Received: 19 November 2018 Accepted: 20 May 2019}

Published online: 13 June 2019

\section{References}

1. Kinane DF, Stathopoulou PG, Papapanou PN. Periodontal diseases. Nat Rev Dis Primers. 2017;3:17038.

2. Vidal F, Cordovil I, Figueredo CM, Fischer RG. Non-surgical periodontal treatment reduces cardiovascular risk in refractory hypertensive patients: a pilot study. J Clin Periodontol. 2013:40(7):681-7.

3. Vergnes JN, Canceill T, Vinel A, Laurencin-Dalicieux S, Maupas-Schwalm F, Blasco-Baque $V$, Hanaire $H$, Arrive $E$, Rigalleau V, Nabet $C$, et al. The effects of periodontal treatment on diabetic patients: the DIAPERIO randomized controlled trial. J Clin Periodontol. 2018;45(10):1150-63.

4. Bertl K, Parllaku A, Pandis N, Buhlin K, Klinge B, Stavropoulos A. The effect of local and systemic statin use as an adjunct to non-surgical and surgical periodontal therapy-a systematic review and meta-analysis. J Dent. 2017;67:18-28.

5. Thongtang N, Diffenderfer MR, Ooi EMM, Barrett PHR, Turner SM, Le NA, Brown W, Schaefer EJ. Metabolism and proteomics of large and smal dense LDL in combined hyperlipidemia: effects of rosuvastatin. J Lipid Res. 2017:58(7):1315-24.

6. Bytyci I, Bajraktari G, Bhatt DL, Morgan CJ, Ahmed A, Aronow WS, Banach M, Lipid, Blood Pressure Meta-analysis Collaboration G. Hydrophilic vs lipophilic statins in coronary artery disease: a meta-analysis of randomized controlled trials. J Clin Lipidol. 2017;11(3):624-37.

7. Cicek Ari V, llarslan YD, Erman B, Sarkarati B, Tezcan I, Karabulut E, Oz SG, Tanriover MD, Sengun D, Berker E. Statins and IL-1beta, IL-10, and MPO levels in gingival Crevicular fluid: preliminary results. Inflammation. 2016;39(4):1547-57.

8. Sakoda K, Yamamoto M, Negishi Y, Liao JK, Node K, Izumi Y. Simvastatin decreases IL-6 and IL-8 production in epithelial cells. J Dent Res. 2006;85(6): 520-3.

9. Thangamani S, Mohammad H, Abushahba MFN, Hamed MI, Sobreira TJP, Hedrick VE, Paul LN, Seleem MN. Exploring simvastatin, an antihyperlipidemic drug, as a potential topical antibacterial agent. Sci RepUk. 2015;5:16407.

10. Mundy G, Garrett R, Harris S, Chan J, Chen D, Rossini G, Boyce B, Zhao M, Gutierrez $\mathrm{G}$. Stimulation of bone formation in vitro and in rodents by statins. Science (New York, NY). 1999;286(5446):1946-9.

11. Jin J, Machado ER, Yu H, Zhang X, Lu Z, Li Y, Lopes-Virella MF, Kirkwood KL, Huang Y. Simvastatin inhibits LPS-induced alveolar bone loss during metabolic syndrome. J Dent Res. 2014;93(3):294-9.

12. Bouitbir J, Singh F, Charles AL, Schlagowski Al, Bonifacio A, Echaniz-Laguna A, Geny B, Krahenbuhl S, Zoll J. Statins trigger mitochondrial reactive oxygen species-induced apoptosis in glycolytic skeletal muscle. Antioxid Redox Sign. 2016;24(2):84-98

13. Khurana S, Gupta S, Bhalla H, Nandwani S, Gupta V. Comparison of antiinflammatory effect of atorvastatin with rosuvastatin in patients of acute coronary syndrome. J Pharmacol Pharmacother. 2015;6(3):130-5.

14. Su Y, Xu Y, Sun YM, Li J, Liu XM, Li YB, Liu GD, Bi S. Comparison of the effects of simvastatin versus atorvastatin on oxidative stress in patients with type 2 diabetes mellitus. J Cardiovasc Pharmacol. 2010;55(1):21-5.

15. Li GM, Zhao J, Li B, Zhang XF, Ma JX, Ma XL, Liu J. The anti-inflammatory effects of statins on patients with rheumatoid arthritis: a systemic review and meta-analysis of 15 randomized controlled trials. Autoimmun Rev. 2018; 17(3):215-25.

16. Ting $M$, Whitaker EJ, Albandar JM. Systematic review of the in vitro effects of statins on oral and perioral microorganisms. Eur J Oral Sci. 2016;124(1):4-10.
17. Sinjab K, Zimmo N, Lin GH, Chung MP, Shaikh L, Wang HL. The effect of locally delivered statins on treating periodontal Intrabony defects: a systematic review and meta-analysis. J Periodontol. 2017;88(4):357-67.

18. Akram Z, Vohra F, Javed F. Efficacy of statin delivery as an adjunct to scaling and root planing in the treatment of chronic periodontitis: A meta-analysis. $J$ Investig Clin Dent. 2018;9(2):e12304.

19. Ambrosio LMB, Rovai ES, Sendyk DI, Holzhausen M, Pannuti CM. Does the adjunctive use of statins provide additional benefits to nonsurgical periodontal treatment? A systematic review and meta-analysis. J Periodontal Res. 2018;53(1):12-21.

20. Muniz F, Taminski K, Cavagni J, Celeste RK, Weidlich P, Rosing CK. The effect of statins on periodontal treatment-a systematic review with meta-analyses and meta-regression. Clin Oral Investig. 2018;22(2):671-87.

21. Meza-Mauricio J, Soto-Penaloza D, Penarrocha-Oltra D, Montiel-Company JM, Peruzzo DC. Locally applied statins as adjuvants to non-surgical periodontal treatment for chronic periodontitis: a systematic review and meta-analysis. Clin Oral Investig. 2018:22(7):2413-30.

22. Moher D, Shamseer L, Clarke M, Ghersi D, Liberati A, Petticrew M, Shekelle P Stewart LA, Grp P-P. Preferred reporting items for systematic review and meta-analysis protocols (PRISMA-P) 2015 statement. Rev Esp Nutr Hum Die. 2016:20(2):148-60.

23. Higgins JP, Green S. Cochrane handbook for systematic reviews of interventions; 2011.

24. Tu YK, Woolston A, Faggion CM Jr. Do bone grafts or barrier membranes provide additional treatment effects for infrabony lesions treated with enamel matrix derivatives? A network meta-analysis of randomizedcontrolled trials. J Clin Periodontol. 2010;37(1):59-79.

25. Dias S, Welton NJ, Caldwell DM, Ades AE. Checking consistency in mixed treatment comparison meta-analysis. Stat Med. 2010;29(7-8):932-44.

26. Spiegelhalter DJ, Best NG, Carlin BR, van der Linde A. Bayesian measures of model complexity and fit. J R Stat Soc Ser B Stat Methodol. 2002:64:583-616.

27. Zhao XJ, Zhou CC, Ma JJ, Zhu YJ, Sun M, Wang PX, Zhang Y, Ma HQ, Zhang $\mathrm{HJ}$. Efficacy and safety of rectal 5-aminosalicylic acid versus corticosteroids in active distal ulcerative colitis: a systematic review and network metaanalysis. Sci Rep-Uk. 2017;7:15.

28. Pradeep AR, Thorat MS. Clinical effect of subgingivally delivered simvastatin in the treatment of patients with chronic periodontitis: a randomized clinical trial. J Periodontol. 2010;81:214-22.

29. Pradeep AR, Priyanka N, Kalra N, Naik SB, Singh SP, Martande S. Clinical efficacy of subgingivally delivered 1.2-mg simvastatin in the treatment of individuals with class II furcation defects: a randomized controlled clinical trial. J Periodontol. 2012;83:1472-9.

30. Rath A, Mahenra J, Thomas L, Sandhu M, Namasi A, Ramakrishna T. A clinical, radiological and IL-6 evaluation of subgingivally delivered simvastatin in the treatment of chronic periodontitis. Int J Drug Deliv. 2012;4(1):70-81.

31. Pradeep AR, Kumari M, Rao NS, Martande SS, Naik SB. Clinical efficacy of subgingivally delivered $1.2 \%$ atorvastatin in chronic periodontitis: a randomized controlled clinical trial. J Periodontol. 2013:84:871-9.

32. Pradeep AR, Rao NS, Bajaj P, Kumari M. Efficacy of subgingivally delivered simvastatin in the treatment of patients with type 2 diabetes and chronic periodontitis: a randomized double-masked controlled clinical trial. J Periodontol. 2013:84:24-31.

33. Rao NS, Pradeep AR, Bajaj P, Kumari M, Naik SB. Simvastatin local drug delivery in smokers with chronic periodontitis: a randomized controlled clinical trial. Aust Dent J. 2013;58:156-62.

34. Pradeep AR, Karvekar S, Nagpal K, Patnaik K, Guruprasad CN, Kumaraswamy KM. Efficacy of locally delivered $1.2 \%$ rosuvastatin gel to non-surgical treatment of patients with chronic periodontitis: a randomized, placebocontrolled clinical trial. J Periodontol. 2015;86:738-45.

35. Kumari M, Martande SS, Pradeep AR, Naik SB. Efficacy of Subgingivally delivered $1.2 \%$ atorvastatin in the treatment of chronic periodontitis in patients with type 2 diabetes mellitus: a randomized controlled clinical trial. J Periodontol. 2016:87(11):1278-85.

36. Pradeep AR, Garg V, Kanoriya D, Singhal S. 1.2\% Rosuvastatin versus $1.2 \%$ atorvastatin gel local drug delivery and redelivery in treatment of Intrabony defects in chronic periodontitis: a randomized placebo-controlled clinical trial. J Periodontol. 2016:87(7):756-62.

37. Garg S, Pradeep AR. 1.2\% Rosuvastatin and 1.2\% atorvastatin gel local drug delivery and redelivery in the treatment of class II furcation defects: a randomized controlled clinical trial. J Periodontol. 2017;88(3):259-65. 
38. Kumari M, Martande SS, Pradeep AR. Subgingivally delivered $1.2 \%$ atorvastatin in the treatment of chronic periodontitis among smokers: a randomized, controlled clinical trial. J Investig Clin Dent. 2017;8(2). https:// doi.org/10.1111/jicd.12213.

39. Pradeep AR, Kanoriya D, Singhal S, Garg V, Manohar B, Chatterjee A. Comparative evaluation of subgingivally delivered $1 \%$ alendronate versus $1.2 \%$ atorvastatin gel in treatment of chronic periodontitis: a randomized placebo-controlled clinical trial. J Investig Clin Dent. 2017;8(3). https://doi.org/10.1111/jicd.12215.

40. S Martande S, Kumari M, Pradeep AR, Pal Singh S, Kumar Suke D. Comparative evaluation of efficacy of subgingivally delivered $1.2 \%$ atorvastatin and 1.2\% simvastatin in the treatment of intrabony defects in chronic periodontitis: a randomized controlled trial. J Dent Res Dent Clin Dent Prospects. 2017;11(1):18-25.

41. Pankaj D, Sahu I, Kurian IG, Pradeep AR. Comparative evaluation of subgingivally delivered $1.2 \%$ rosuvastatinand $1 \%$ metformin gelin treatment of intrabony defects in chronic periodontitis: a randomized controlled clinical trial. J Periodontol. 2018;89(11):1318-25.

42. Martande SS, Kumari M, Pradeep AR, Singh SP, Suke DK, Guruprasad CN. Platelet-rich fibrin combined with 1.2\% atorvastatin for treatment of Intrabony defects in chronic periodontitis: a randomized controlled clinical trial. J Periodontol. 2016;87(9):1039-46.

43. Fentoglu O, Kirzioglu FY, Ozdem M, Kocak H, Sutcu R, Sert T. Proinflammatory cytokine levels in hyperlipidemic patients with periodontitis after periodontal treatment. Oral Dis. 2012;18(3):299-306.

44. Surve SM, Acharya AB, Thakur SL. Efficacy of subgingivally delivered atorvastatin and simvastatin as an adjunct to scaling and root planing. Drug Metab Pers Ther. 2015;30:263-9.

45. Emani S, Gunjiganur GV, Mehta DS. Determination of the antibacterial activity of simvastatin against periodontal pathogens, Porphyromonas gingivalis and Aggregatibacter actinomycetemcomitans: an in vitro study. Contemp Clin Dent. 2014;5(3):377-82.

46. Luan Z, Chase AJ, Newby AC. Statins inhibit secretion of metalloproteinases$1,-2,-3$, and -9 from vascular smooth muscle cells and macrophages. Arterioscler Thromb Vasc Biol. 2003;23(5):769-75.

47. Song CL, Guo ZQ, Ma QJ, Chen ZQ, Liu ZJ, Jia HT, Dang GT. Simvastatin induces osteoblastic differentiation and inhibits adipocytic differentiation in mouse bone marrow stromal cells. Biochem Bioph Res Co. 2003;308(3):458-62.

48. Maeda T, Matsunuma A, Kurahashi I, Yanagawa T, Yoshida H, Horiuchi N. Induction of osteoblast differentiation indices by statins in MC3T3-E1 cells. J Cell Biochem. 2004;92(3):458-71.

49. Jansen JP, Fleurence R, Devine B, Itzler R, Barrett A, Hawkins N, Lee K, Boersma C, Annemans L, Cappelleri JC. Interpreting indirect treatment comparisons and network meta-analysis for health-care decision making: report of the ISPOR task force on indirect treatment comparisons good research practices: part 1. Value Health. 2011;14(4):417-28.

50. Jeong C, Kim SE, Shim KS, Kim HJ, Song MH, Park K, Song HR. Exploring the in vivo anti-inflammatory actions of simvastatin-loaded porous microspheres on inflamed tenocytes in a collagenase-induced animal model of Achilles tendinitis. Int J Mol Sci. 2018;19(3). https://doi.org/10. 3390/ijms19030820.

51. Dalcico R, de Menezes AM, Deocleciano OB, Oria RB, Vale ML, Ribeiro RA, Brito GA. Protective mechanisms of simvastatin in experimental periodontal disease. J Periodontol. 2013;84(8):1145-57.

52. Chen YJ, Chang LS. Simvastatin induces NFkappaB/p65 down-regulation and JNK1/C-Jun/ATF-2 activation, leading to matrix metalloproteinase-9 (MMP-9) but not MMP-2 down-regulation in human leukemia cells. Biochem Pharmacol. 2014;92(4):530-43.

53. Messora MR, Apolinario Vieira GH, Vanderlei J, Mariguela VC, Fernandes PG, Palioto DB, Scombatti de Souza SL, Novaes AB Jr, Furlaneto F, Taba M Jr. Rosuvastatin promotes benefits on induced periodontitis in hypertensive rats. J Periodontal Res. 2017;52(4):734-44.

54. Sonnenschein SK, Meyle J. Local inflammatory reactions in patients with diabetes and periodontitis. Periodontology 2000. 2015;69(1):221-54.

55. Polak D, Shapira L. An update on the evidence for pathogenic mechanisms that may link periodontitis and diabetes. J Clin Periodontol. 2018;45(2):150-66.

56. Katz J, Caudle RM, Bhattacharyya I, Stewart CM, Cohen DM. Receptor for advanced glycation end product (RAGE) upregulation in human gingiva fibroblasts incubated with nornicotine. J Periodontol. 2005;76(7):1171-4.

57. Katz J, Yoon TY, Mao S, Lamont RJ, Caudle RM. Expression of the receptor of advanced glycation end products in the gingival tissue of smokers with generalized periodontal disease and after nornicotine induction in primary gingival epithelial cells. J Periodontol. 2007;78(4):736-41.

\section{Publisher's Note}

Springer Nature remains neutral with regard to jurisdictional claims in published maps and institutional affiliations.

\section{Ready to submit your research? Choose BMC and benefit from:}

- fast, convenient online submission

- thorough peer review by experienced researchers in your field

- rapid publication on acceptance

- support for research data, including large and complex data types

- gold Open Access which fosters wider collaboration and increased citations

- maximum visibility for your research: over $100 \mathrm{M}$ website views per year

At BMC, research is always in progress.

Learn more biomedcentral.com/submissions 